\title{
"Cross-Disability" in India?: On the limits of Disability as a Category and the Work of Negotiating Impairments
}

Michele Friedner, Nandini Ghosh and Deepa Palaniappan

\section{(2) OpenEdition}

\section{Journals}

\section{Electronic version}

URL: http://journals.openedition.org/samaj/4516

DOI: $10.4000 /$ samaj.4516

ISSN: $1960-6060$

\section{Publisher}

Association pour la recherche sur l'Asie du Sud (ARAS)

\section{Electronic reference}

Michele Friedner, Nandini Ghosh and Deepa Palaniappan, «"Cross-Disability" in India?: On the limits of Disability as a Category and the Work of Negotiating Impairments », South Asia Multidisciplinary Academic Journal [Online], Free-Standing Articles, Online since 05 April 2018, connection on 30 April 2019. URL : http://journals.openedition.org/samaj/4516 ; DOI : 10.4000/samaj.4516

This text was automatically generated on 30 April 2019.

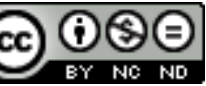

This work is licensed under a Creative Commons Attribution-NonCommercial-NoDerivatives 4.0 International License. 


\title{
"Cross-Disability" in India?: On the limits of Disability as a Category and the Work of Negotiating Impairments
}

\author{
Michele Friedner, Nandini Ghosh and Deepa Palaniappan
}

We thank the passionate and generous disability rights activists with whom we engage for both their insights into this article and the work they are doing to create a more habitable world. We also thank three anonymous reviewers for SAMAJ for their excellent feedback and suggestions and Jules Naudet for being a wonderful editor. Finally, we offer this essay in Javed Abidi's memory: Javed was one of India's leading disability rights activists and he passed away on March 4, 2018. He will be missed.

1 In June 2016, Michele attended an annual three-day meeting of disability activists from all over India held in Bangalore. ${ }^{1}$ There were blind, deaf, orthopedically-disabled, and leprosy-cured attendees from different Indian states. The event convener, a leading disability rights activist, opened the meeting by stressing that this was a cross-disability event articulated around a cross-disability platform. What he meant by "cross-disability" was that people from all disability categories were included and the meeting would therefore be representative of all of their distinct interests and needs. However, he immediately corrected himself, specifying that the event was lacking representation from individuals with psychosocial disabilities. He stressed this was unfortunate because the event was therefore not truly representative.

Over the course of the three days, attendees primarily discussed issues of physical accessibility relating to the Indian Railways, the National Building Code, the development of Indian "smart cities," and elections. There was also some (critical) discussion of the central government's Accessible India Campaign, which was launched in 2015, has been heavily publicized, and is devoted to making India's infrastructure accessible to disabled people. While accessibility was discussed broadly and attempts were made to include all the categories of those present, there was tension with different disability constituencies 
attempting to foreground their own issues in relation to accessibility. This is also complicated, as no two people with the same disability are identical.

On the third day of the event, a deaf attendee mentioned that he had worked with a group of people to conduct an access audit of a prominent public building in Patna, Bihar. The convener immediately asked him if there had been participants from other disability categories involved in the audit (such a question appeared to manifest distrust in the inclusiveness of the effort). The deaf man replied that only deaf people participated because there were no sign language interpreters available. He stated that once when he tried to write back and forth to communicate with an orthopedically-disabled person with whom he was working, the process was too slow; he was thus trying to explain why the audit was not conducted with "cross-disability" representation. Immediately following this revelation about the lack of sign language interpreters in Patna, there was a discussion about the number of sign language interpreters in India (a technical discussion of numbers), but it quickly fizzled out and the group moved on to other things. Thus the "cross-disability" umbrella is always a tenuous one, with the concerns of specific groups assuming importance from time to time, but never for too long.

4 At various points the discussion focused on issues specific to orthopedically-disabled people-the need for ramps and wheelchair access on the Indian railways and the lack of physically accessible hotel rooms for wheelchair users. At other times, it focused on blind peoples' need for print material and election materials in accessible formats, for example. And at the end of the three days, one of the attendees stressed that it would be important for the disability movement to focus on the needs of deaf and blind people, as they were the most left out or left behind in the disability movement. This was a notable statement as so often in Indian disability politics and organizing, there is a focus on generic broader concepts such as "accessibility" and "disability rights" (as discussed throughout the majority of the conference), and such concepts do not necessarily address the specificity of individual disability categories (and their distinct needs). Indeed, invoking specific impairment needs is often viewed as being "selfish" (we have all heard disabilitymovement participants use this terminology), while being "cross-disability" is seen as being inclusive. Disability-movement participants thus move back and forth between the specificity of their own disabilities and generality, in the sense of being invested in a "cross-disability" movement. As a leading disability activist told us: "I used to joke in the early days of my involvement with the disability movement, 'It's supposed to be crossdisability advocacy, not cross-purpose disability advocacy!' Today, I'd say that there's a veneer of disability bhai-bhai [brotherhood], but not much improvement in people's understanding of other disabilities." We are thus interested in the work that this "veneer" does.

5 "Cross-disability" is a "technomoral" concept (Bornstein and Sharma 2016:17) and serves as a unifying meta-narrative for the mainstream disability movement, which we argue is a Delhi- and urban-based movement with close connections to the state and to international funding streams. As Bhambani (2004) notes, the movement was spearheaded by the Disability Rights Group (DRG) which was formed in 1994 by a group of Delhi-based disability activists to lobby India's policy makers to pass disability legislation. The DRG was clearly inspired by leaders of the United States disability movementspecifically, Judy Heumann and Justin Dart-who they met in a satellite-video call organized by the American consulate. Heumann and Dart stressed that the passing of the Americans with Disabilities Act resulted from a sustained campaign by a self-help 
advocacy movement of disabled people, and encouraged Indian activists to do the same (Bhambani 2004:28). Notably, the emergence of the DRG followed the launch of the Asian and Pacific Decade of Disabled Persons (1993-2002) and the increased exposure to international disability initiatives this facilitated. As such, as the group's name suggests, it is heavily influenced by "cross-disability" rights-based frameworks and discourses.

Invoking "cross-disability" organizing, needs, and desires is a way of exerting a moral presence and making a claim, especially to international funders (such as members of the International Disability Alliance) that valorize such work. Indeed, the DRG had set itself up as a cross-disability organization that works towards the promotion of disability rights, which has influenced the disability movement and disability politics in India in the long run. Operating on a cross-disability rights-based platform is at odds with a legislative and judicial structure based upon "compensatory discrimination" (Galanter 1984) that includes specific quotas for specific diagnostic labels. In the United States context, Scotch and Barnartt (2001) analyze the emergence of the American disability movement and make a distinction between cross-disability and impairmentspecific claims that movement participants make. According to them, cross-disability claims are broad-based and refer to umbrella concepts such as inclusion and accessibility while impairment-specific claims are more detailed and specific and deal with the particular accommodations and practices needed for each impairment group. In their analysis, they argue that the success of the U.S.-based disability movement and the ultimate passage of the 1990 Americans with Disabilities Act is based on its ability to negotiate between the two kinds of claims. However, as we shall see, India's two disability Acts in 1995 and 2016 have been tightly tethered to specific disability categories, such as blindness, deafness, and orthopedic disability, for example. Inclusion in the disability category thus always has a constitutive outside. Who is included and on what grounds? What kinds of compromises by disability activists are required to create "cross-disability" inclusion? These are questions to which we attempt to respond in this article.

7 To be sure, disabled people and disability studies scholars have long talked about what might be called "access conflicts" when one person's access needs impinge on another person's: for example, one person might need to rock back and forth and flap their hands while another person might require a quiet and stimulus-free environment; or one person might use a guide dog and another person might be severely allergic to dogs. Indeed, deaf Indians told Michele repeatedly that what is most important to them is recognition of Indian Sign Language and the existence of Indian Sign Language interpreters. Yet, Michele has heard blind and orthopedically-disabled people talk about the benefits of cochlear implants, a surgically-implanted electronic device, and express the opinion that interpreters should not be needed; disability activists themselves do not understand the needs, desires, and preferences of other groups (and note that cochlear implants are a techno-medical solution that is very contentious in deaf communities around the world).

While disability studies scholars in India, mirroring an "intersectional turn" in disability studies more broadly, have attended to the ways in which disabled people negotiate differences such as gender (Ghai 2003; Ghosh 2016; Mehrotra 2006) and caste (Mehrotra 2013; Palaniappan 2016), we argue that it is also important to consider the ways in which different disability categories are negotiated and the ways in which current state structures create conditions of (im)possibility for disability categories to be rendered commensurable and/or for diverse disabled people to come together. We also 
argue that an analysis of the work of disability categorization provides a novel approach to thinking about structural inclusion and exclusions in relation to bodily difference because the state has seemingly committed itself to including additional disabilities-and thus additional people-under new legislation in 2016. We stress that both disabled activists and the state are beholden to competing and contradictory frameworks: a social welfare-based framework of compensatory discrimination as well as a rights-based framework as put forward by the United Nations and international funding agencies and organizations. We do not take a normative or prescriptive stance toward these frameworks.

9 We draw from ethnographic research conducted in diverse locations around India during the period from 2008-2017. ${ }^{3}$ In writing this essay, we draw on time spent together and separately at various disability conferences, programs, and events; on semi-structured interviews and informal conversations with disabled interlocutors, including disability movement leaders in urban and rural areas, disabled people from different class, religious, and caste backgrounds, Indian and international NGO administrators, and with parents of disabled children; and on conducting participant-observation with various NGOs and funding organizations working in the field of disability. We draw from our different research vantage points to examine both top-down and bottom-up approaches to mobilizing the concept of "cross-disability," as to be sure, the concept is used by a wide range of stakeholders. We see this case of "cross-disability" organizing as contributing to scholarship on Indian social movements, particularly those that have a stake in reservations as a main form of welfare and (re)distribution. Diverse physical, sensory, and cognitive abilities and needs make the process of representative claims-making (Saward 2006) especially fraught and serve to create multiple publics within a broader movement (Fraser 1990). Building upon scholars such as Viswanath (2015), we are interested in how performing representation might result in fragmentation as different groups lobby for their own interests.

\section{Category Trouble}

10 While the emerging discipline of disability studies has productively inserted the category of disability into scholarly conversations, ${ }^{4}$ we argue that it is important to consider the work that the category does. We are specifically interested in the kinds of differences that it obscures as well as the disconnects between academic and activist use of discourses (as discourses do circulate from academia into both activist and everyday spaces). Disability is unique in that its associated legislative-juridical structure and accompanying social and political movements include diverse conditions and embodiments such as cerebral palsy, schizophrenia, and deafness, for example. People are required to engage in different kinds of social, communicative, representational, and political work to come together under this category. Matthew Kohrman asks:

If the recent and ongoing emergence of disability as a space of psycho-somatosocial production is contingent on the proliferation of modernist institutional frameworks, including those constitutive of nation-states, by what means might these institutional frameworks formally fix boundaries around what is disablement and what is not? By what processes might such institutional apparatuses make disablement not just more perceivable in local contexts but codified such that some locally understood differences and alterities are included and some excluded? (Kohrman 2003:7) 
We both answer and depart from this question in an Indian context in that we consider the ways that "cross-disability" comes to be an uneasy umbrella category that can hinder real improvements in the lives of people with specific experiences and needs. Indeed, the meta-narratives that the "cross-disability" movement mobilizes, such as the need for accessibility and inclusion, are incommensurable with how the state operates. The mainstream disability movement's advocacy narratives are incompatible with the state approach which sees disability as a social welfare category dealt with by fragmented schemes such as concessions for free transport, monthly welfare pensions, marriage allowances, and student scholarships, etc. The disconnect between the state's welfareoriented actions and the mainstream disability movement's desires-based upon a rights framework-is evident in the mainstream disability movement's concerns about the marriage allowance given to non-disabled people who marry a disabled person, for example. While state officials see positive value in offering funds to those willing to marry a disabled person, the mainstream movement finds this initiative to be based on charity and not empowerment. ${ }^{5}$

11 Our argument is that the logic of "cross-disability" deliberately obscures differences and people with different disabilities are required to mitigate their differences and focus on the commonness of their discrimination, which is difficult to identify, as it varies from one disability category to another. Deaf people might need Indian Sign Language interpreters while orthopedically-disabled people might need ramps, for example. More than this, "cross-disability" benefits the state in that it prevents concrete, material claims from being made. "Cross-disability" also benefits NGOs that have largely moved away from impairment-specific work to being one-size-fits-all disability organizations, whereby they are able to increase the numbers of people served and demonstrate their impact to funders. (Although note that we have found that because deaf people are more mobile, many of these NGOs often wind up serving larger numbers of deaf people, particularly in metro locations [see Friedner 2015 on "one-size-fits-all" disability NGOs]).

\section{Structure and Legislation in India: from 1995 to 2016}

In an Indian context, disability functions as a political and social category, based on a biological premise-similar to the categories of caste and gender, where bodies form the basis of the ideological creation of hierarchies that create and sustain structural oppression, as well as discriminatory attitudes and practices. These attitudes and practices are to be mitigated through legislative affordances, that offer positive discrimination in order to ensure the upliftment of marginalized groups (Galanter 1984). However, disadvantage is translated into differential social and political stakes depending on what kind of disability one has. The state, while acknowledging the political and social valences of disability as a concept, recognizes disabled people only in so far as they fall into specific disability categories, such as blind, deaf, and orthopedically disabled as examples, in order to ensure that different impairment categories are (differentially) figured into the schemes of positive discrimination. Thus, while activists and disability studies scholars largely critique the "medical model" (or viewing disability through the lens of biological impairment and as something to be fixed) and shun it in favor of the "social model," (or viewing disability as created by society as a result of infrastructure, policies, and practices established for certain kinds of bodies), claims in an Indian context are broadly based upon the medical model. ${ }^{6}$ 
13 In India's "biobureaucracy" (Kohrman 2005), the unmarked category of disability does not carry any weight beyond vague non-discrimination clauses, unless it is attached to specific impairments. Notably, India's first major disability legislation, the Persons with Disabilities (Equal Rights and Full Participation) Act 1995, listed impairment categories that were to be recognized as disabilities-"blindness, low vision, leprosy-cured, hearing impairment, locomotor disability, mental retardation, and mental illness." These impairment categories and the degree of the impairment were to be certified by government medical authorities in order to access benefits provided by the state or to be eligible for reservations in higher education and government jobs. The Act provided specific employment quotas in public-sector jobs to people with such impairments: $1 \%$ for blindness and low vision; $1 \%$ for hearing impairment; and $1 \%$ for locomotor disability. The same kind of quota breakdown also existed in central universities/higher education institutions, as these higher-educational qualifications are required to apply for government jobs. Similarly, the Act specified the identification of jobs that could be performed by people belonging to different impairment categories, based on the assumption that people with different impairments can only perform specific kinds of jobs. This is very much a "medical model"-framing in that people are only considered disabled if they have diagnosed and recognized impairments; it is, in Ian Hacking's (1986) productive phrase, a making up of certain categories of people. What this does is, on the one hand, create exclusions of all those people with impairments who are not recognized by the law, and on the other hand, institute structural inequality among the selected groups of disabilities by reserving education and employment for some while denying the same to the others.

In 2007 India signed and ratified the United Nations Convention on the Rights of Persons with Disabilities (UNCRPD), which does not talk about the needs of specific disability categories except in Article 24, which focuses on education. In this article, the importance of signed languages for deaf people and braille for blind people is discussed (and there was significant debate over the inclusion of signed languages in the act as Kauppinen and Jokinen [2014] discuss). The UNCRPD has been enthusiastically embraced by many mainstream Indian disability activists who have been working to harmonize Indian disability law with the convention, under the mantra of moving from "welfare to rights" and the importance of "disability rights" in general. In addition, activists embraced the fact that the UNCRPD represented a move away from a "medical model" approach towards a more "social model" one in which specific disability categories are not as important and there is a focus on changing society-schools, workplaces, and public and private spaces-and ensuring the participation of all people in everyday activities and institutions. The UNCRPD is considered an example of "social model" legislation as disability is seen as being an interactional process that occurs when an individual's impairment interacts with the environment; it puts forth a relational understanding of how disability occurs (Lid 2014) (although it does not prescribe how different disability categories are supposed to relate to each other).

India's signing and ratifying of the UNCRPD led to a lengthy process of drafting and revising a new act, which started in 2009 and resulted in a new law, the Rights of Persons with Disabilities (RPD) Act 2016 to replace the 1995 Act, to be discussed in the following section. The major task of drafting the new law was entrusted to a committee in which representation was ensured by including representatives of as many disability categories as possible. However disability-specific groups-such as victims of acid attacks, people 
with learning disabilities, and people with chronic neurological and blood disorders, as examples-who were not part of this committee lobbied continuously for the inclusion of their disability category in the law in order to qualify for state benefits. This process of consultation demonstrated both contestation within disability categories (which, again, benefits certain disabled people).

\section{Consultation and Contestation: Rights of Persons with Disabilities Act 2016}

16 The ideals of representation in consultation-and the consultation process itself-existed very much in relation to the already-existing quota structure in which individuals with orthopedic, visual, and hearing disabilities were privileged. In talking about the consultation process with mainstream disability-rights leaders, Michele learned that they felt the disability-specific categories of quotas were in violation of the UNCRPD and that a new disability act developed after ratifying the UNCRPD should not have employment and higher education quotas. However the fractured movement and the specific advocacy groups within the disability sector (which include the single identity groups of deaf, blind, and orthopedically-disabled people, parents' associations of intellectually-disabled children, and "cross-disability" urban activist groups located in New Delhi and other cities) ensured that the disability quota in employment and higher education remained, now expanded to 5\%, and added the inclusion of 9 new categories of impairment/ disabling conditions. In addition, the number of disability categories included in the new RPD Act was increased to 21 and included autism, thalassemia, hemophilia, and sickle-cell anemia, among other categories. ${ }^{7}$

Being added to the disability category extends legal benefits in terms of providing (vague) non-discrimination protection and accommodation in employment and education environments. ${ }^{8}$ However, despite the addition and inclusion of these new categories, the majority will not be eligible for quotas in employment and higher education because they must qualify as "benchmark" disabilities, the new term introduced in the RPD Act to refer to disabled people who have at least $40 \%$ impairment as certified by a medical authority and which gives them certain entitlements. The term "benchmark disability" confuses more than it illuminates: by using a generic definition of disability, the law recognizes all persons who face barriers in society as disabled people entitled to accommodation, but only certain categories of benchmark individuals qualify for employment and higher education quotas. This is as such double tier legislation that only affords concrete benefits to certain categories of people. State entities have, both in the past and currently, drawn up lists of jobs appropriate for different kinds of disabilities. These lists may result in certain categories of persons with benchmark disabilities being excluded from the benefits of the state, as they may not be deemed suitable for employment. This happened recently in Delhi, with an MA graduate without the use of his arms being denied employment by government entities: he was "too disabled." Drawing up lists and establishing criteria is a mechanism that specifies which kind of job can be done by a person with which kind of impairment-one hand, one leg, and one eye are common terms which actually thus provide opportunities only to people with the mildest forms of impairment and deny most disabled people the chance to secure government employment. 

from even accessing most of the state benefits. There is an elaborate (but not fool-proof) certification mechanism that involves visiting a hospital for a medical examination in order to receive a percentage-based gradation to be eligible to access benefits (see Kochhar [2013] on this process), and this is unique only to the disability category in India; note that members of other legislated groups such as members of caste and tribe communities do not have such a percentage system. Despite this percentage system, what most people in newly created disability categories are not yet aware of is the fact that disability benefits or even the ability to self-advocate and consolidate group rights is a rarity for many disability categories except for blind, deaf and orthopedic impairments; these categories have historically monopolized the "benchmark" disabilities. ${ }^{9}$ impairments) as defined by the state, there are often power struggles related to the application of the benchmark disability quotas. For example, during the consultations leading up to the passage of the new 2016 Act, there was a vocal group of blind activists who argued they did not want to share their quota with low-vision people because they feared people with some vision would be preferred to those who are completely blind when it came to hiring. Similarly, deaf people did not want to share their quota with people who were hearing impaired but not deaf. For example, deaf people in Chennai, Tamil Nadu told Michele they did not want to share their quota with hearing-impaired people who could lip-read and speak, as they were the ones who often got jobs. Each impairment group wanted "their own" quota that they did not have to share with other categories (especially categories considered to be "less disabled"), in order to access employment more easily. Thus there is tension even within disability categories.

Disability activists told Michele stories about disability-specific concerns that they were willing to give up in exchange for other concessions and a disability movement leader told her another movement leader made statements such as: "I am willing to give this up for orthopedic disabilities so you please give something up for mental disability"-there was a constant back-and-forth negotiation over what impairment-specific claims to foreground and what impairment-specific claims should be considered non-negotiable. During the discussions and debates around the Act, notably, very few "cross-disability" issues were discussed. The most intense concern was around specific impairment categories such as: Do blind people have to share their employment quota with people with low vision?; Do people with intellectual impairments have the right to open bank accounts and exercise legal capacity?; and, Will autism and deafblindness be included as disability categories in the Act?

We consider two themes that emerged in the debates on the first draft of the Act in 20132014, which foreground tensions around different disability categories and competing interests. The draft was circulated widely and translated into local languages so that grassroots-level consultations could take place across the country, mostly in the state capitals, and feed into the final law. The first theme is the inclusion of disability categories-the argument for including more categories was countered by the claim that more categories meant more claimants for the limited welfare provisions, which would mean that the dominant categories might be deprived of the same. Stakeholders engaged in boundary work and policing of disability categories and were concerned about whether some of the proposed categories were health conditions and not disabilities-for example whether hemophilia and sickle-cell disease could be considered disabilities. In addition, 
the conversations were dominated by the urban-based leaders of the disability movement, who primarily represented the categories of visual, hearing and orthopedic disabilities. The legislative-juridical process in India has always relied on defining disability through top-down medicalized disability categories and this has influenced all so-called rights-based groups to lay claim to welfare entitlements based on labels, which are both medical and administrative. Thus the main concerns even during the framing of the law had to do with what disability categories to include while not losing benefits already granted in the 1995 law. These seemed to be gatekeeping debates in that the voices of the minority disability category groups were almost drowned out by constituencies from dominant disability categories, whose members perhaps feared losing their powerful command over discourse and resources.

The second debate theme was the issue of legal capacity. Here the debates were between the dominant impairment categories on the one hand and parents' groups (parents of children and adults with disabilities such as autism and other intellectual disabilities, for example) on the other. As the UNCRPD granted full legal capacity to all persons with disabilities, rights-oriented groups had ensured that the provision for legal capacity had been included in the draft bill using the same language as in the UNCRPD. This clause was fully supported by persons living with mental illness, who felt that being tagged as mentally ill made a person vulnerable to legal incapacity, in which case families and communities could incarcerate them for years. However, parents' groups, especially parents of people with intellectual impairments and autism, expressed their anxieties over the concept of full legal capacity as many felt their children were incapable of ever exercising full legal capacity, and would thus become vulnerable to exploitation, which could endanger not only their assets but also their lives. Nandini remembers that during one of these consultations on the law in Kolkata, parents' groups expressed their anguish over the provision because they felt that there were almost no support mechanisms for their children. Conversely, the other dominant groups insisted that there had to be a vision for full legal capacity to ensure mechanisms would be put in place by the state. For parents who had experienced the limits of state-led welfare provisions and perfunctory awarding of guardianship, a structure that would allow for full legal capacity and for protection for their children was nearly impossible to conceive of and they felt the other groups were dismissive of their concerns. A compromise over the provision was reached by proposing the concept of limited guardianship-limits both in terms of time and responsibility so that people with different impairments could be empowered to take on more legal capacity over time. ${ }^{10}$ These two themes foreground the often tense negotiations that take place among stakeholders coming from different embodied disability experiences and categories on a "cross-disability" platform.

Note that the initial version of the Act was not passed in the end-the reasons included lack of political will and commitment in the government, to bureaucratic reluctance to accept proposals that lead to dilution of the provisions, which resulted in many groups within the disability sector protesting such a perfunctory piece of legislation (as there were attempts to "rush" the Act through in the final days of the Congress party's rule in 2014). With the failure to pass the Act, there were many negative feelings among people involved in the disability movement. Indeed, discussions had become so acrimonious, with personal character attacks going back and forth, and it became especially clear to us that working together on a "cross-disability" platform was difficult. In 2014, Michele and Deepa organized a roundtable to discuss the aftermath of the failure of the bill at 
Jawaharlal Nehru University (JNU) in New Delhi where attendees wondered if it even made sense to talk about a "disability community" anymore. The participants, mostly $\mathrm{PhD}$ students with disabilities, discussed the ongoing RPD debates and raised concerns about the logic of considering the disability movement as a pan-national, pan-disability idea, and whether it were increasingly a movement controlled by a few disability groups and powerful NGOs in major cities.

To be sure, contestation around benchmark categories permeates everyday life, beyond consultation on the legislative-juridical process, and poses possibilities and limits for "cross-disability" relating and coalition-building, as evidenced in these examples taken from JNU in New Delhi that foreground on-going tensions around recognized benchmark categories. ${ }^{11}$ In early 2017, a job vacancy for the Visually Impaired (VI) category was announced in the JNU Centre for Political Studies. Ultimately, after interviewing a number of eligible visually impaired candidates, the university administration hired a candidate with an orthopedic impairment. This led to widespread anger among visuallyimpaired people in academia, which spread to social media as well, against a bias favoring orthopedically-disabled people in employment. What is interesting to consider as well is that within the university-based student disability movement at JNU, blind students have always been active and well-knit. JNU has a unique students' movement-based organization called JNU Vision, which is a collective of visually impaired students on the campus, and this group had taken up issues concerning cross-disability topics as well as issues specifically affecting the lives of students with vision impairments. There is also another parallel organization JNUDPA (JNU Disabled Persons Association) which is an earlier consolidation of students and staff with disabilities, traditionally consisting of persons with orthopedic impairments. Both the groups function simultaneously at JNU, converging together and supporting each other during rights-based protests and mobilizations. An example of this a protest that students with visual impairments held about the presence of stray dogs on campus, as many students had been bitten. Orthopedically-disabled students came out in solidarity to support their visuallyimpaired peers.

Impairment categories never seem to exist alone but are always seen in relation to each other. We have had conversations with disability activists, scholars, NGO administrators, and funding agencies in which we are asked our opinion about disability hierarchies. We are asked who are the most disadvantaged in society, for example and those who ask us are usually asking us to think about the main three categories: the deaf, blind, and orthopedically disabled. These interrogations often seek to subdue all other identity markers like caste, class, gender, religion, ethnic identity etc. to assume that disability is the overwhelmingly-dominant marginalized identity; indeed, we stress that we see issues of class, religion, and caste as being backgrounded and not taken up by activists. To be sure, there are divisions but these again map onto disability categories and who is "deserving" of entitlements. Kusters (2017) has written about how disabled people who ride in Mumbai's overcrowded "handicapped" train compartments constantly assess each other in order to determine who is worthy of seats and who has the right to ride in the compartment. As she writes, people are often thrown out of the compartment or told that they should give up their seats to other people who are seemingly more disabled. This raises the following issue: every list of categories always has a constitutive outside, an impairment that is not included but could or should be (Brown 1995). 


\section{Conclusion: Back to Particularities?}

\section{inclusive and it can easily list additional impairment and disease categories in the} "disabled" category. This inclusion of additional categories (in name only) can occur because the state's responsibilities vanish beyond the $4 \%$ and $5 \%$ reservation in employment and higher education, vague non-discrimination clauses, and token inclusion in general social welfare schemes, as outlined in this essay. While sub-groups (i.e., blind and visually impaired people) fight for entitlements within their respective reservation quotas, the state continues to ignore its responsibilities towards more marginalized impairments and disorders. For instance, there is an alarming crisis looming in India with regard to an increase in the number of carriers of these disorders. The increase in the number of carriers of hemophilia, thalassemia and sickle-cell anemia, especially among poor people with little or no access to health screening facilities, is a matter that needs immediate state intervention (see, for example Indian Pediatrics [2007]). In addition to screening, there are other issues such as access to medication and blood transfusion because without them, people with such disorders have will die due to the inaction of the state (and this resonates with Gupta's [2012] work on bureaucracy and structural violence in India). This is already happening in states like Bihar and Jharkhand where death is increasingly an unfortunate and common side-effect of being born with a blood disorder. (Unlike elsewhere in the world, death is more common than treatment in non-metro rural areas in India. ${ }^{12}$ ) This is an example of "a grave national crisis becom [ing] unexceptional, a matter of routine administration, a problem largely uncommented upon in the press or in parliament, and nameable only through banalities on the occasions when it is mentioned." (Gupta 2012:20).

The mainstream disability movement ought to be wary of the state casually incorporating additional diseases and impairments into the disability category, not because these are not important, but because the state seemingly has no intention of providing specific structures or practices to abate them. Recognition through inclusion does not result in any substantial benefits or changes to the status quo. For the state, the (expanding) disability category might become a destination island for all resource-draining diseases and impairments. Instead of focusing more on individual needs, it will be easier to assign a generic/universalizing disability status, giving the illusion that employment and education reservations will accrue to these impairments. However, as we have discussed, the elusive employment and education reservations are shrouded within the "benchmark disabilities" clause in the RPD Act. As a result, "cross-disability" as a platform is now more dangerous than ever, especially for non-stable impairment groups who need more interventions and treatments to stay alive or healthy. ${ }^{13}$

We argue thus that the disability movement in India has to unpack its cross-disability framework and re-work strategies to begin specific impairment-related claims, especially for those types of impairments where treatment and other support is needed on a daily basis. "Cross-disability" was once (and is still) useful to bring disability awareness to the state and general public and it is now time to do justice to those groups of impairmentsboth newly added and old-as per their specific needs. A cross-disability organization that highlights oppression and discrimination as a common experience of all disabled people, yet presses for specific solutions to address the differing needs of different impairment

South Asia Multidisciplinary Academic Journal , Free-Standing Articles 
categories, can potentially build solidarity to ensure that the state introduces proactive measures for disabled people across the country. In fact, "cross-disability" can bring together people with different disabilities into collectives that focus on building disability identities positing common discrimination and making claims for shared entitlements. ${ }^{14}$ At the same time, is it possible to maintain a holistic "cross-disability" framework for the purposes of external advocacy, while retaining individual differences and categories for the purpose of internal disability-movement negotiations? What would it mean to categorically name and discuss each impairment group, instead of using terms like "people with disabilities" at least during conversations within the disability movement?

In addition, we argue for more attention paid to the work in which diverse disabled people engage, in order to assemble themselves into a "cross-disability" platform. More research is needed on the kinds of social and political work that disabled people across impairment categories carry out in order to make themselves legible to each other and to actualize some kind of universalizing "disability identity." In addition, while we have attended here to the deployment of "cross-disability" discourse, additional work is needed on how disabled leaders and activists themselves understand and feel about this discourse. As we have noted, "cross-disability" functions as a "technomoral" (Bornstein and Sharma 2016) claim, although, as a result of how Indian disability law, policies, and practices are structured and implemented, this claim does not do much except perhaps to link disabled Indian activists more tightly to international funding circles and discourses such as those put forth in the UNCRPD, with the exception of when the claim is used by grass-roots groups to advocate for and demand basic entitlements. ${ }^{15}$ While disability studies scholars have largely discounted the medical model in favor of the social model, more research is needed on contexts in which the medical model is still the norm by which entitlements are distributed and the category of disability is rendered legible.

\section{BIBLIOGRAPHY}

Anand, Shilpaa. 2016. "The Models Approach in Disability Scholarship: An Assessment of its Failings." Pp. 23-38 in Interrogating Disability in India, edited by N. Ghosh. New Delhi: Springer India.

Barnes, Colin and Geof Mercer. 2010. Exploring Disability. Cambridge and Malden: Polity Press. Bhambani, Meenu. 2004. "From Charity to Self-Advocacy: The Emergence of Disability Rights Movement in India." MA thesis, Department of Disability and Human Development, University of Illinois at Chicago.

Bornstein, Erica and Aradhana Sharma. 2016. "The Righteous and the Rightful: The Technomoral Politics of NGOs, Social Movements, and the State in India." American Ethnologist 43(1):76-90.

Brown, Wendy. 1995. States of Injury: Power and Freedom in Late Modernity. Princeton: Princeton University Press.

Chaudhry, Vandana. 2015. "Neoliberal Disorientations: Changing Landscapes of Disability and Governance in India.” Disability \& Society 30(8):1158-73. 
Dhanda, Amita. 2007. "Legal Capacity in the Disability Rights Convention: Stranglehold of the Past or Lodestar for the Future?" Syracuse Journal of International Law and Commerce 34:429-62.

Fraser, Nancy. 1990. "Rethinking the Public Sphere: A Contribution to the Critique of Actually Existing Democracy." Social Text 25(26):56-80.

Friedner, Michele. 2015. Valuing Deaf Worlds in Urban India. New Brunswick: Rutgers University Press.

Galanter, Marc. 1984. Competing Inequalities: Law and the Backwards Classes in India. New Delhi: Oxford University Press.

Ghai, Anita. 2003. (Dis)embodied Form: Issues of Disabled Women. Har-Anand Press: New Delhi.

Ghosh, Nandini. 2016. Impaired Bodies, Gendered Lives: Everyday Realities of Disabled Women. Delhi: Primus Books.

Gupta, Akhil. 2012. Red Tape: Bureaucracy, Structural Violence, and Poverty in India. Durham: Duke University Press.

Hacking, Ian. 1986. “Making Up People.” Pp. 222-36 in Reconstructing Individualism: Autonomy, Individuality, and the Self in Western Thought, edited by T. C. Heller, M. Sosna, and D. E. Wellbery. Stanford: Stanford University Press.

Indian Pediatrics. 2007. "Prevention of Thalassemia in India." Retrieved April 4, 2018 (http:// www.indianpediatrics.net/sep2007/sep-647-648.htm).

Kauppinen, Liisa, and Markku Jokinen. 2014. "Including Deaf Culture and Linguistic Rights." Pp. 131-45 in Human Rights and Disability Advocacy, edited by M. Sabatello and M. Schulze. Philadelphia: University of Pennsylvania Press.

Kausar, Heena. 2017. "Campus Calling: DU to Reserve Seats for Acid Attack Survivors, Students with Thalassemia." Hindustantimes, May 25. Retrieved April 4, 2018 (http:// www.hindustantimes.com/delhi-news/campus-calling-du-to-reserve-seats-for-acid-attacksurvivors-students-with-thalassemia/story-wd8KjOABKsN8F3at8KlHSO.html).

Kochhar, Rijul. 2013. "The Analytics of Disability: Bodies, Documents, and the Order of the State." MA thesis, Department of Sociology, Delhi School of Economics, University of Delhi.

Kohrman, Matthew. 2005. Bodies of Difference. Berkeley: University of California Press.

Kusters, Annelies. 2017. "Autogestion and Competing Hierarchies: Deaf and Other Perspectives on Diversity and the Right to Occupy Space in the Mumbai Suburban Trains." Social \& Cultural Geography 18(2):201-23.

Lid, Inger Marie. 2014. "Universal Design and Disability: An Interdisciplinary Perspective." Disability and Rehabilitation 16:1344-49.

Mehrotra, Nilika. 2016. "A Resource Book on Disability Studies in India." Centre for the Study of Social Systems, School of Social Sciences, Jawaharlal Nehru University. Retrieved April 4, 2018 ( http://www.jnu.ac.in/Faculty/nilika/A\%20READER\%200N\%20DISABILITY\%20STUDIES\%20IN\% 20INDIA.pdf).

Mehrotra, Nilika. 2013. "Disability, Gender, and Caste Intersections in the Indian Economy." Pp. 295-324 in Disability and Intersecting Statuses (Research in Social Science and Disability, Volume 7), edited by B. Altman, and S. Barnartt. Emerald Group Publishing Limited.

Mehrotra, Nilika. 2006. "Negotiating Gender and Disability in Rural Haryana." Sociological Bulletin 55(3):406-26 
Purohit, Jugal R. 2017. “Acid Attack Survivors, Thalassemia Students to Have Reserved Seats in DU.” India Today, May 25. Retrieved April 4, 2018 (http://indiatoday.intoday.in/education/story/ du-seats-reserved/1/962690.html).

Palaniappan, Deepa. 2016. "Inner Marginalities and Sub-Group Politicization within the Disability Movement.” Café Dissensus. Retrieved February 26, 2018 (https://cafedissensus.com/2016/08/14/ inner-marginalities-and-sub-group-politicization-within-the-disability-movement/).

Saward, Michael. 2006. “The Representative Claim.” Contemporary Political Theory 5:297-318.

Scotch, Richard and Sharon Barnartt. 2001. Disability Protests: Contentious Politics 1970-1999.

Washington DC: Gallaudet University Press.

Soldatic, Karen, and Shaun Grech. 2014. "Transnationalising Disability Studies:

Rights, Justice and Impairment." Disability Studies Quarterly 34(2). Retrieved February 26, 2018 ( http://dsq-sds.org/article/view/4249).

Viswanath, Rupa. 2015. "Commissioning Representation: The Misra Report, Deliberation, and the Government of the People in Modern India." South Asia: Journal of South Asian Studies 38(3):495511.

\section{NOTES}

1. We have changed the name of the city as well as some other identifying details throughout the text in order to protect participants' anonymity.

2. Erica Bornstein and Aradhana Sharma (2016:77) define "technomoral" as the complex, strategic integration of technical and moral vocabularies into political tactics.

3. Michele is a medical anthropologist who has mostly worked with sign language-using deaf young adults in urban locations in India including Bangalore, Delhi, and other cities. Nandini is a sociologist who has experience working with and researching disability issues in India in both urban and rural contexts, in Eastern, Southern and North Eastern India. Deepa, a researcher with training in both special education and political science, is currently doing community-based livelihood work with the disabled in rural Bihar. She has conducted field research with Disabled Peoples Organizations in rural and urban Madhya Pradesh, Jharkand, Bihar, Assam, and Tamil Nadu.

4. For information on disability studies in India, see Mehrotra (2016).

5. But note that this outrage around the pension is also evidence of a disconnect between urbanbased mainstream disability-movement participants and rural disabled people. In her fieldwork in rural north India, Deepa observed that disabled people and their families were adamant about the importance of this marriage allowance.

6. For an overview of medical and social models in relation to disability, see Barnes and Mercer (2010). But see Anand (2016) on the problems of using such models in an Indian context.

7. In the case of blood disorders-thalassemia, hemophilia, and sickle-cell anemia-there has not been a widely known history of association with the broader disability community. During the debates prior to the RPD Act coming into force, thalassemic and hemophilic advocates worked to be included as part of the definition of disability.

8. While working in Bihar, Deepa learned about a child with hemophilia who had been unable to progress to the next grade on account of not meeting the required number of school days. His long periods of hospitalization had led to lengthy absences from school. But currently his experience has taken a positive turn after the RPD Act, as the Hemophilia Society Bihar chapter 
has now been able to appeal to or confront the school administration, citing the fact that hemophilia is a disability.

9. The following news articles discuss reservations in higher education for new categories of disabled students: Kausar (2017); Purohit (2017).

10. See Dhanda (2007) on the issue of legal capacity in the UNCRPD more broadly and note too that issues of legal capacity also arise in relation to other disability categories, such as leprosy.

11. Note that JNU blind-student activism is quite specific to its campus as a result of the history of the blind movement in Delhi, blind-student organizing at JNU and the creation of distinct social spaces for blind people on campus, as well as the fact that students live on campus; student politics at other universities might take on other forms.

12. In the first week of July 2017 a young hemophilia patient died in Patna, Bihar after falling down. The incident was not reported in the media. This is the second such instance Deepa has heard of in a period of just a few months through Hemophilia Patna chapter community members.

13. Also at stake, with the inclusion of new categories, is the question of access to healthcare and the role that the state plays in providing healthcare, as some of these new additions to the disability category have greater needs in terms of medical intervention; people need treatment in addition to non-discrimination clauses.

14. We are of course wary of the kinds of forced collectivities discussed by Chaudhry (2015) in her work with disabled self-help groups in rural Andhra Pradesh.

15. While outside the scope of this article, the category of "cross-disability" often functions differently outside of urban locales. Nandini and Deepa have both observed examples of productive cross-impairment mobilization in rural India. Cross-disability groups have been formed with the vision of uniting people with different impairments, to help them to realize that, as disabled people, they are oppressed, and then to collectively demand rights from the state and society specifically in relation to livelihood issues and access to social security schemes.

\section{ABSTRACTS}

This essay analyzes the stakes involved when a movement claims to be "cross-disability" in India. Activists, disabled peoples' organizations, and non-governmental organizations devoted to disability often claim that their work and focus is "cross-disability" and that all categories of disability are included within their purview. Drawing on ethnographic fieldwork conducted with various disability organizations and disabled people in India between 2008-2017, we argue that the "cross-disability" category obscures tensions that exist between different categories of disability, while benefiting the state and civil society. Moreover, performing representation results in fragmentation as different groups lobby for their own interests. We analyze the social and political work that the categories "cross-disability" and "disability" do in everyday worlds in India and analyze new forms of disability inclusions and exclusions that have emerged in the aftermath of a 2016 disability law.

\section{INDEX}

Keywords: disability, impairment, social movements, categories, reservations, development 


\section{AUTHORS}

\section{MICHELE FRIEDNER}

Department of Comparative Human Development, University of Chicago, USA

\section{NANDINI GHOSH}

Department of Sociology, Institute of Development Studies Kolkata, India

\section{DEEPA PALANIAPPAN}

Independent researcher and consultant, India 